\title{
USO DE ÁGUA RESIDUÁRIA DE ORIGEM URBANA NO CULTIVO DE GÉRBERAS: EFEITO NOS COMPONENTES DE PRODUÇÃO
}

\section{SALOMÃO DE S. MEDEIROS ${ }^{1}$, FREDERICO A.L. SOARES ${ }^{2}$, HANS R. GHEYI ${ }^{3}$, PEDRO D. FERNANDES ${ }^{3}$}

\begin{abstract}
RESUMO: Com este trabalho, teve-se o objetivo de determinar a viabilidade de quatro lâminas de águas residuárias de origem urbana $(75 ; 100 ; 125$ e 150\% da evapotranspiração da cultura) na produção de gérbera (Gerbera jamesonni), tipo comercial Rambo, comparando-se os resultados com os obtidos por meio da adoção do manejo convencional (adubação orgânica, química e irrigação com água de abastecimento equivalente a $100 \%$ da evapotranspiração). O experimento foi realizado em casa de vegetação, na Universidade Federal de Campina Grande, de fevereiro a julho de 2006, abrangendo um ciclo completo de produção. O delineamento experimental foi em blocos casualizados, com três repetições, e as variáveis monitoradas foram: número de botões florais emitidos e intervalo de emissão; número de flores colhidas e intervalo entre colheitas; diâmetro das flores e comprimento das hastes. Para as variáveis monitoradas, apenas o comprimento das hastes foi afetado significativamente pelas lâminas de água residuária aplicadas. A adoção do manejo com água residuária foi melhor que o convencional, em todas as variáveis, com exceção de comprimento das hastes, constatando-se que esse tipo de água constitui recurso importante no suprimento hídrico e de nutrientes para a cultura da gérbera, potencializando produtividade compatível ou melhor que o uso de técnicas de produção convencional.
\end{abstract}

PALAVRAS-CHAVE: flores, fertirrigação, Gerbera jamesonni.

\section{WASTEWATER USE OF URBAN ORIGIN IN CULTIVATION OF GERBERAS: EFFECT ON PRODUCTION COMPONENTS}

\begin{abstract}
The objective of the present study was to evaluate the viability of four depths (equivalent to $75 ; 100 ; 125$ and $150 \%$ of crop evapotranspiration) of wastewater from urban origin in production of gerbera (Gerbera jamesonni), commercial type Rambo and contrast the results obtained with those adopting conventional management (organic and chemical manuring and irrigation with urban supply water equivalent to $100 \%$ evapotranspiration). The experiment was conducted on a greenhouse of Universidade Federal de Campina Grande - PB - Brazil, during February to July 2006, during a complete cycle of production. The experimental design consisted of randomized blocks with three replications. The variables monitored were number of flowers buds and emission interval, number of flowers collected and interval of harvest, diameter of flowers and length of flower stems. For the monitored variables, only length of flower stem presented significant effect among the depths of irrigation with wastewater. The adoption of management with wastewater showed superiority for the variables evaluated in relation to conventional management except the length of flower stem. These results demonstrate that the use of wastewater constitutes an important source for supply of nutrients and water to gerbera crop increasing the potential of compatible productivity or better than the conventional production techniques.
\end{abstract}

KEYWORDS: flowers, fertigation, Gerbera jamesonni.

\footnotetext{
${ }^{1}$ Eng ${ }^{o}$ Agrícola, Doutor, Gerência Regional de Infra-Estrutura e Irrigação, CODEVASF - 2ª SR/Bom Jesus da Lapa - BA, Fone: (0XX77) 3481.4424, salommao@gmail.com.

${ }^{2}$ Eng $^{\circ}$ Agrônomo, Prof. Doutor, Departamento de Engenharia Agrícola, UFCG, Campina Grande - PB.

${ }^{3}$ Eng $^{\circ}$ Agrônomo, Prof. Doutor, Departamento de Engenharia Agrícola, UFCG, Campina Grande - PB.

Recebido pelo Conselho Editorial em: 8-11-2006
}

Aprovado pelo Conselho Editorial em: 6-7-2007

Eng. Agríc., Jaboticabal, v.27, n.2, p.569-578, maio/ago. 2007 


\section{INTRODUÇÃO}

O uso planejado de águas residuárias implica necessidade menor de captação dos recursos hídricos primários e de geração reduzida de efluentes, constituindo-se, portanto, em estratégia eficaz para a conservação desse recurso natural, em seus aspectos qualitativos e quantitativos.

Muitos países localizados em regiões áridas e semi-áridas têm incluído a reutilização da água no planejamento de recursos hídricos, haja vista que a escassez de água de boa qualidade tem limitado o desenvolvimento urbano, industrial e agrícola. Nesse sentido, os efluentes estão constituindo parte integrante do plano nacional dos recursos hídricos de vários países (TANJI, 1997; BOUWER, 2000). Em alguns casos, como Jordânia e Arábia Saudita, tem havido uma política nacional para reutilização de todos os efluentes gerados (PESCOD, 1992). Em determinadas regiões do México e da costa desértica do Peru, como consequiência do desequilíbrio dos recursos hídricos, somado ao crescimento acelerado das cidades, as atividades agrícolas foram seriamente afetadas, tornando obrigatório e urgente o uso das águas residuárias como única alternativa para sobrevivência, viabilizando a irrigação de mais de 400.000 ha (LÉON \& CAVALLINI, 1996).

Segundo VAN DER HOEK et al. (2002), as maiores vantagens do aproveitamento da água residuária para fins agrícolas residem na conservação da água disponível e na possibilidade de aporte e reciclagem de nutrientes (reduzindo a necessidade de fertilizantes químicos), concorrendo para a preservação do meio ambiente.

No Brasil, são escassos os registros de utilização de água residuária para fins agropecuários, exceto na produção de cana-de-açúcar, o que não significa que essa prática não ocorra (BASTOS, 2003), principalmente em periferias das grandes cidades, onde são cultivadas, geralmente, olerícolas e forrageiras para alimentação animal (KONIG et al., 1998). O uso em olerícolas é questionável por se tratar de culturas alimentares.

Estima-se que, atualmente, o mercado mundial de flores e de plantas ornamentais movimente cerca de US\$ 49 bilhões anuais; desse total, 42,8\% do volume de vendas são representados pelo segmento de flores, $39,8 \%$ por plantas, $8,8 \%$ por bulbos e $8,6 \%$ na forma de folhagens (JUNQUEIRA \& PEETZ, 2004).

As exportações brasileiras de flores e plantas ornamentais vêm aumentando a cada ano, passando de US\$ 19,4 milhões em 2003 (crescimento de 30,2\% em relação ao ano anterior JUNQUEIRA \& PEETZ, 2004), para US\$ 29,6 milhões em 2006 (www.hortica.com.br); as exportações consistiram de flores de corte, com destaque para rosas, crisântemos, gipsófilas, cravos, gérberas, solidago, lírios e helicônias; dentre elas, as gérberas têm grande potencial, por seu alto valor de mercado, possibilidade de serem exploradas por mão-de-obra familiar, gerando emprego e renda em pequenas áreas e em periferias de cidades, podendo, ainda, ser irrigadas com águas residuárias, em razão de não se constituírem em cultura alimentar.

A origem das gérberas é no sul da África; são plantas perenes, herbáceas, da espécie Gerbera jamesonni, família Asteraceae, cujas flores são compostas; na natureza, são encontradas na coloração que varia do amarelo ao laranja-escuro, mas, com o desenvolvimento de plantas híbridas, surgiram no mercado genótipos com grande variedade de cores, abrangendo desde a branca, branco-neve, cor-de-rosa, vermelha, carmim e, até mesmo, a violeta (GUISELINI, 2002).

Considerando que a floricultura nordestina vem-se firmando como importante atividade econômica e tendo em vista a necessidade de identificar fontes alternativas de água para fins agrícolas, realizou-se este trabalho com o propósito de avaliar a viabilidade do uso de águas residuárias de origem urbana na produção de gérberas.

\section{MATERIAL E MÉTODOS}

O experimento foi conduzido em casa de vegetação pertencente à Unidade Acadêmica de Engenharia Agrícola (UAEAg), da Universidade Federal de Campina Grande - UFCG, no período 
de 26-2-2006 a 25-7-2006. As coordenadas geográficas do local são: 7¹5'18” de latitude sul, 35'52'28" de longitude oeste e altitude de $550 \mathrm{~m}$; o clima da região, conforme a classificação climática de Köeppen, adaptada ao Brasil (COELHO \& SONCIN, 1982), é do tipo Csa, que representa clima mesotérmico, subúmido, com período de estiagem quente e seco (4 a 5 meses) e período chuvoso de outono a inverno.

A cultura utilizada foi a gérbera, tipo comercial Rambo, cujas mudas foram obtidas por meio de cultura de tecido junto à BioLab Tecnologia Vegetal Ltda., já aclimatadas e transplantadas em vasos plásticos com capacidade de $5 \mathrm{~L}$.

Utilizou-se de solo franco-arenoso, não-salino, para preenchimento dos vasos (substrato), cujos atributos químicos, obtidos por meio de análises realizadas no Laboratório de Irrigação e Salinidade - LIS, da UFCG, de acordo com a metodologia proposta pela EMBRAPA (1997), constam na Tabela 1 .

TABELA 1. Atributos químicos do solo utilizado no experimento.

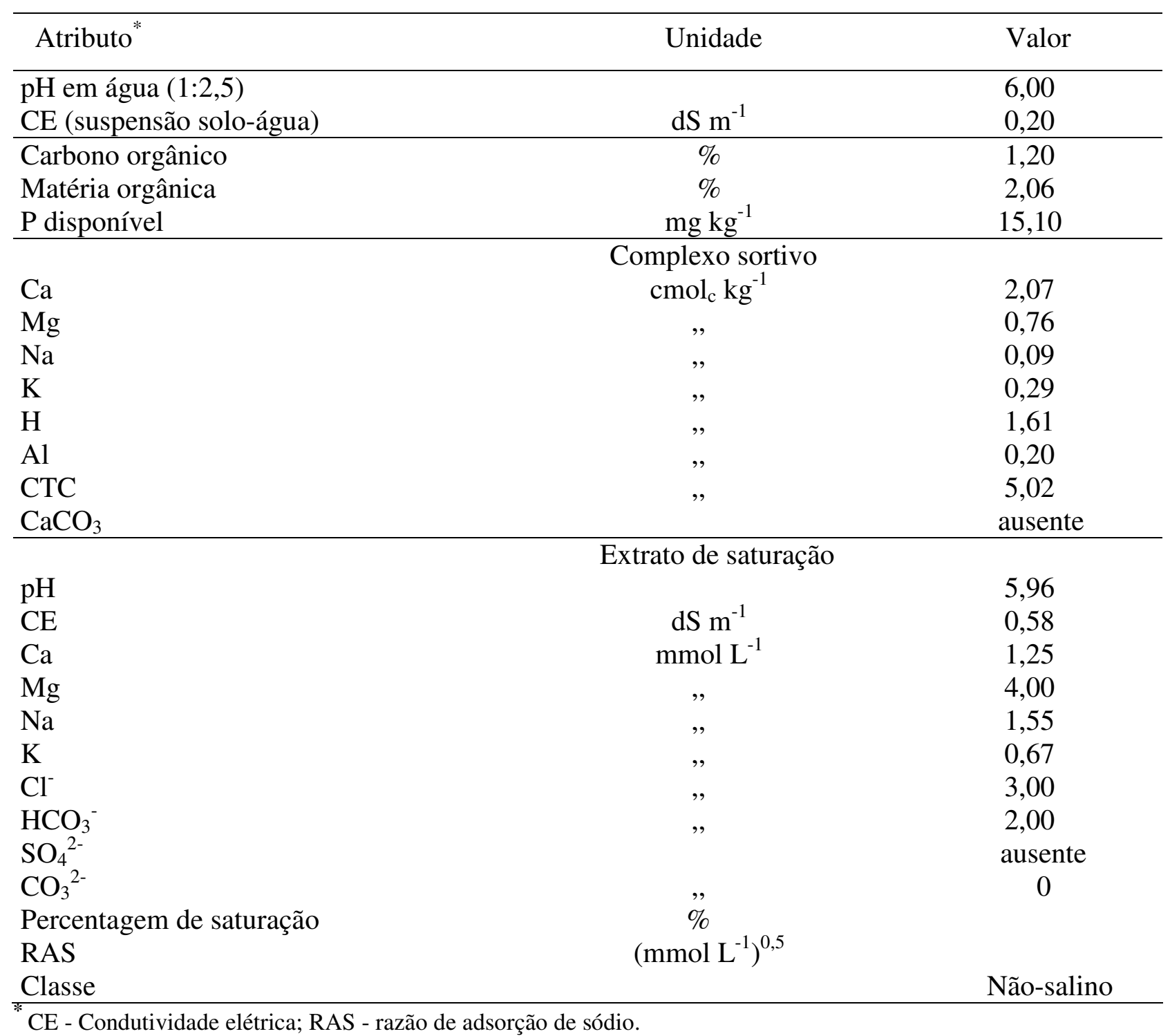

O experimento foi instalado no esquema de blocos ao acaso, com três repetições, tendo, em cada bloco, os tipos de manejo adotados: convencional - MC (adubação orgânica, química e irrigação com água de abastecimento, equivalente a $100 \%$ da evapotranspiração da cultura (ETc) $\mathrm{T}_{1}$ ) e com água residuária de origem urbana - MR (quatro lâminas de água residuária, equivalentes a 75; 100; 125 e $150 \%$ da ETc, correspondendo aos tratamentos $\mathrm{T}_{2}, \mathrm{~T}_{3}, \mathrm{~T}_{4}$ e $\mathrm{T}_{5}$, respectivamente), 
distribuídos ao acaso, em que a parcela experimental se compõe de 12 plantas, totalizando 36 plantas por tratamento.

Realizaram-se, no tratamento $\mathrm{MC}$, uma adubação orgânica e outra química; a primeira consistiu da aplicação de $2 \%$ de húmus, em base de peso seco (100 g por vaso), enquanto a química foi realizada com base em recomendações da BioLab ${ }^{1}$. Na fase inicial, a cada evento de irrigação, foram aplicados $28 \mathrm{~mL}$ por planta de uma solução contendo 200; 50 e $100 \mathrm{mg} \mathrm{L}^{-1}$ de $\mathrm{N}$, P e K, respectivamente, enquanto, na fase de produção, a solução continha $100 ; 50$ e $200 \mathrm{mg} \mathrm{L}^{-1} \mathrm{de} \mathrm{N}, \mathrm{P} \mathrm{e}$ $\mathrm{K}$, respectivamente, com aplicações diárias e com o mesmo volume utilizado na fase inicial.

A água residuária utilizada no experimento era proveniente do córrego 'Monte Santo' que passa pela área experimental da UAEAg, oriunda de bairros próximos ao Câmpus da UFCG, captada por meio de um tonel de PVC (capacidade de $200 \mathrm{~L}$ ); a água não foi submetida a nenhum tipo de tratamento, exceto a uma filtragem no ponto de captação com tela de náilon $(\varnothing=2 \mathrm{~mm})$ em torno do tonel, com o objetivo de apenas remover os sólidos grosseiros.

Para estimar os aportes de nutrientes às plantas por meio das lâminas de água residuária aplicadas, a cada irrigação, foi coletada uma alíquota $(100 \mathrm{~mL})$ de água, armazenando-as em freezer; e fez-se, ao final de cada mês, uma amostra composta para determinação de pH, condutividade elétrica - CE, concentrações de N, P, K, Ca, Mg, Zn, Cu, Fe, Mn e Na, conforme metodologia da APHA (1997).

$\mathrm{Na}$ Tabela 2, apresentam-se os atributos químicos das águas de abastecimento e residuárias, de origem urbana, utilizadas como tratamentos. Dentre os parâmetros monitorados, os que apresentaram maiores oscilações (coeficiente de variação) durante o período, foram os micronutrientes $\mathrm{Zn}, \mathrm{Cu}, \mathrm{Fe}$ e $\mathrm{Mn}$, mantendo-se os demais estáveis.

TABELA 2. Atributos químicos da água de abastecimento e residuária de origem urbana utilizadas no experimento.

\begin{tabular}{|c|c|c|c|c|c|c|c|c|c|c|c|c|c|}
\hline \multirow[b]{2}{*}{ Mês } & \multirow{2}{*}{$\mathrm{pH}$} & $\mathrm{CE}_{\mathrm{a}}$ & P-Total & K & N-Total & $\mathrm{Na}$ & $\mathrm{Ca}$ & $\mathrm{Mg}$ & $\mathrm{Zn}$ & $\mathrm{Cu}$ & $\mathrm{Fe}$ & $\mathrm{Mn}$ & \multirow{2}{*}{$\begin{array}{c}\text { RAS } \\
\left(\mathrm{mmol} \mathrm{L}^{-1}\right)^{0,5}\end{array}$} \\
\hline & & $\left(\mathrm{dS} \mathrm{m} \mathrm{m}^{-1}\right)$ & \multicolumn{10}{|c|}{ - } & \\
\hline \multicolumn{14}{|c|}{ Água de Abastecimento } \\
\hline & 7,5 & 0,38 & nd & 5,47 & nd & 35,65 & 20,00 & 15,80 & nd & nd & nd & nd & 1,45 \\
\hline \multicolumn{14}{|c|}{ Água Residuária de Origem Urbana } \\
\hline abril & 8,6 & 1,04 & 3,31 & 28,13 & 23,80 & 159,60 & 76,00 & 36,48 & 0,002 & 0,220 & 0,001 & 0,040 & 3,76 \\
\hline maio & 8,6 & 1,10 & 3,98 & 30,47 & 28,80 & 171,70 & 51,40 & 47,76 & 0,010 & 0,004 & 0,001 & 0,000 & 4,14 \\
\hline junho & 8,6 & 1,15 & 3,67 & 30,47 & 33,90 & 181,30 & 64,40 & 43,80 & 0,020 & 0,004 & 0,001 & 0,020 & 4,27 \\
\hline julho & 8,4 & 1,00 & 3,30 & 30,00 & 28,50 & 170,00 & 62,60 & 44,96 & 0,011 & 0,076 & 0,001 & 0,015 & 4,00 \\
\hline Média & 8,4 & 1,13 & 3,59 & 29,81 & 28,60 & 170,52 & 63,48 & 43,20 & 0,01 & 0,08 & 0,00 & 0,02 & 4,04 \\
\hline$\overline{\text { C.V. (\%) }}$ & 4,8 & 13,12 & 8,03 & 3,25 & 12,55 & 4,52 & 13,75 & 9,65 & 59,78 & 116,03 & 57,74 & 110,55 & 4,63 \\
\hline
\end{tabular}

No início do experimento (23-2-2006), todos os vasos foram elevados à capacidade de campo com a respectiva água (abastecimento ou residuária). No intuito de estimar a evapotranspiração da cultura (ETc), foi instalado um lisímetro de drenagem (Figura 1A) em cada bloco, utilizando-se de plantas extras, porém com as mesmas características das demais, e adubadas de acordo com as recomendações da BioLab e do fornecedor das mudas. Obteve-se o volume de água consumido (evapotranspiração) por meio da diferença entre o volume de água aplicado e o drenado, em cada bloco. Estabeleceu-se turno de rega de dois dias, na fase inicial, e diariamente, na fase de produção e, ainda, que o volume aplicado deveria proporcionar, no máximo, drenagem de $100 \mathrm{~mL}$ nesse intervalo; no entanto, durante a primeira semana, foi adicionado volume de $400 \mathrm{~mL}$ a cada dois dias, para determinar qual o volume médio a ser aplicado que atendesse a tal critério; porém, quando se observava que o volume drenado se aproximava de zero, aumentava-se gradualmente o

\footnotetext{
${ }^{1}$ Comunicação pessoal do Diretor Técnico da Biolab: José Barbosa Cabral
} 
volume aplicado, reduzindo-o, por outro lado, quando o volume drenado se aproximava de $100 \mathrm{~mL}$ ou superava esse limite.

(A)

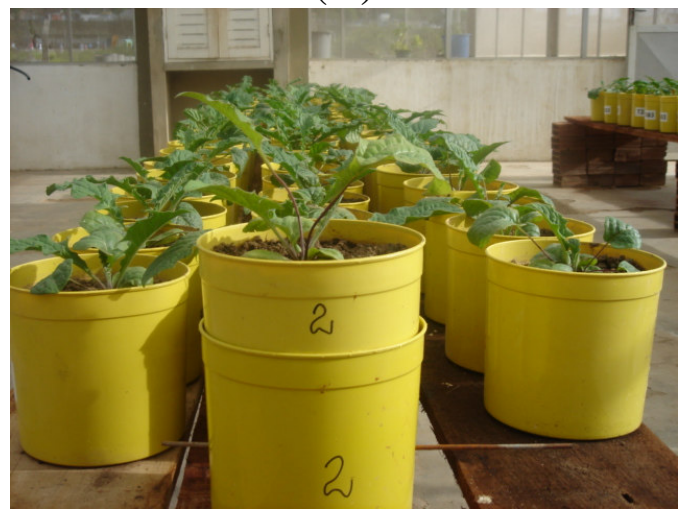

(B)

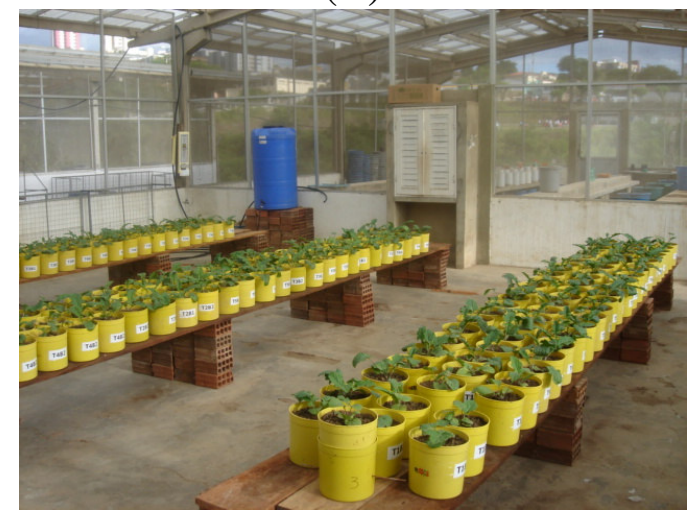

FIGURA 1. Lisímetro de drenagem (A), e vista geral do experimento (B).

O período de monitoramento das variáveis de produção (número de botões florais emitidos e intervalo de emissão; número de flores colhidas e intervalo entre colheitas; diâmetro das flores e comprimento das hastes) foi de 150 dias após o transplantio e, a cada cinco dias, quantificado o número de botões florais emitidos, e a cada dois o número de flores colhidas.

A interpretação dos resultados deu-se por meio da análise de variância, determinando-se a influência das lâminas de água residuária aplicadas nas variáveis de produção; optou-se, também, por testar um contraste (com o nível máximo de significância de 5\% de probabilidade) a fim de verificar as diferenças médias entre as variáveis monitoradas, em resposta ao tipo de manejo adotado (MR e MC).

Para as análises estatísticas, foi utilizado o software SAEG 5.0 (FUNARBE, 1993).

\section{RESULTADOS E DISCUSSÃO}

Avaliando-se a adequabilidade das águas de abastecimento e residuária (Tabela 2), de acordo com as diretrizes apresentadas por AYERS \& WESTCOT (1999), constata-se que, do ponto de vista da salinidade (fator que provoca efeitos sobre a disponibilidade de água às plantas) e da ocorrência de problemas de infiltração no solo, todas possuem grau de restrição de ligeiro a moderado; registrou-se exceção no mês de março, em que não houve qualquer restrição de uso para a água residuária.

Quanto à toxicidade de íons específicos (caso de sódio e cloreto), não se encontrou restrição na água de abastecimento; já a residuária apresentou grau de restrição de ligeiro a moderado. No tocante ao $\mathrm{pH}$, foram elevados os valores nas águas residuárias em relação ao da água de abastecimento, porém, em todos os casos, os valores se enquadram em faixa normal $(6,0-8,4)$ para irrigação, segundo AYERS \& WESTCOT (1999). Dentre os parâmetros monitorados, os que apresentaram maiores oscilações (coeficiente de variação) durante o período de estudos, foram os micronutrientes $\mathrm{Zn}, \mathrm{Cu}$, Fe e Mn, mantendo-se os demais estáveis.

$\mathrm{Na}$ Tabela 3, apresentam-se os aportes de nitrogênio, de fósforo e de potássio às plantas, por meio da adubação química convencional (T1), recomendada para o cultivo de gérbera, e pela aplicação das lâminas de água residuária de origem urbana ( $\mathrm{MR}-\mathrm{T}_{2}$ a $\mathrm{T}_{5}$ ), após 150 dias do transplantio. A adoção do manejo com água residuária suplantou as quantidades de $\mathrm{N}, \mathrm{P}$ e $\mathrm{K}$ aplicadas no manejo convencional ( $\mathrm{MC}-\mathrm{T}_{1}$ ). $\mathrm{O}$ incremento de $\mathrm{N}$ proporcionado pela aplicação de água residuária foi de $85 ; 150 ; 210$ e $270 \%$; o de $\mathrm{P}$ chegou a $25 ; 50 ; 100$ e $150 \%$ e o de $\mathrm{K}$ a 39; 86; 132 e $179 \%$, correspondentes, respectivamente, aos tratamentos $\mathrm{T}_{2}, \mathrm{~T}_{3}, \mathrm{~T}_{4}$ e $\mathrm{T}_{5}$. Ressalta-se que, nos tratamentos $\mathrm{T}_{4}$ e $\mathrm{T}_{5}$, houve drenagem em razão da lâmina aplicada; portanto, ocorreu lixiviação de parte dos nutrientes. Salienta-se que, pela análise do solo, realizada ao final da fase deste 
experimento (resultados não apresentados neste trabalho), registraram-se aumento de $\mathrm{pH}, \mathrm{CE}, \mathrm{Ca}$, $\mathrm{Mg}$ e de $\mathrm{Na}$, em todos os tratamentos, e diminuição de $\mathrm{H}$, Al, matéria orgânica e $\mathrm{P}$ disponível, sem relação direta com os tratamentos.

TABELA 3. Aportes de nitrogênio, fósforo e potássio aplicados às plantas, via adubação mineral (convencional) e por meio da água residuária de origem urbana, após 150 dias do transplantio.

\begin{tabular}{|c|c|c|c|c|}
\hline \multirow{3}{*}{ Tratamento } & \multirow{3}{*}{$\begin{array}{l}\text { Lâmina } \\
\text { mm }\end{array}$} & \multicolumn{3}{|c|}{ Aporte de Nutrientes } \\
\hline & & $\mathrm{N}$ & $\mathrm{P}$ & $\mathrm{K}$ \\
\hline & & \multicolumn{3}{|c|}{ g planta $^{-1}$} \\
\hline $\mathrm{T}_{1}$ & & 0,20 & 0,04 & 0,28 \\
\hline $\mathrm{T}_{2}$ & 522 & 0,37 & 0,05 & 0,39 \\
\hline $\mathrm{T}_{3}$ & 694 & 0,50 & 0,06 & 0,52 \\
\hline $\mathrm{T}_{4}$ & 865 & 0,62 & 0,08 & 0,65 \\
\hline $\mathrm{T}_{5}$ & 1.036 & 0,74 & 0,10 & 0,78 \\
\hline
\end{tabular}

$\mathrm{T}_{1}$ - manejo convencional com água de abastecimento, atendendo a $100 \%$ da ETc; $\mathrm{T}_{2}, \mathrm{~T}_{3}, \mathrm{~T}_{4}$ e $\mathrm{T}_{5}$ - manejo com água residuária, atendendo a 75; 100; 125 e 150\% da ETc, respectivamente.

Resultados de pesquisas com diversas culturas (algodão - FEIGIN et al., 1978, 1984; milho AL-JALOUD et al., 1995; berinjela - AL-NAKSHABANDI et al., 1997; alface - SANDRI, 2003, e café - MEDEIROS, 2005, e SOUZA, 2005) têm corroborado que a aplicação de água residuária de origem urbana tem grande potencial de suprir, parcial ou totalmente, as exigências nutricionais das culturas; ressalta-se, todavia, que o aporte de nutrientes $(\mathrm{N}, \mathrm{P}$ e K) às culturas pela água residuária é influenciado por sua composição e pela lâmina aplicada.

Têm-se, na Figura 2, as médias e o modelo de regressão ajustados às variáveis de produção em função dos tratamentos com água residuária. Para as variáveis número de botões florais emitidos, número de flores colhidas, intervalo de emissão dos botões florais e de colheita de flores, e diâmetro das flores, não se observaram efeitos significativos das lâminas de água residuária aplicadas.

O número médio de flores colhidas por planta (Figura 2B), durante os cinco meses em que durou este experimento, foi igual a 4,4, com intervalo médio de colheita de 34,25 dias (Figura 2D); estimando-se para um ano, resultaria em produção de 10,66 flores por planta, valor relativamente baixo em relação ao índice de 25,62 flores por planta ao ano informado pela BioLab Tecnologia Vegetal Ltda ${ }^{1}$. Ressalta-se, entretanto, que, ao longo dos ciclos de crescimento e produção, as plantas emitem novas brotações que resultam em flores, explicando a diferença para os valores deste trabalho.

Quanto ao diâmetro das flores, observa-se ter sido de $12 \mathrm{~cm}$ o seu valor médio (Figura 2E); comparando-se esse valor com os apresentados pela BioLab $(13 \mathrm{~cm})$, nota-se que a aplicação de água residuária produziu flores com diâmetro ligeiramente inferior $(7,69 \%)$. Já para a variável comprimento das hastes, o efeito da lâmina de água foi significativo, e o modelo que melhor se ajustou, foi o quadrático, indicando aumento no comprimento das hastes à medida que houve incremento da lâmina aplicada, atingindo seu valor máximo $(43,96 \mathrm{~cm})$ para a lâmina de $839 \mathrm{~mm}$, que corresponde à ETc média diária de $5,59 \mathrm{~mm}$ ou $120 \%$ da ETc. Em comparação com as normas de qualidade da IBRAFLOR (2000), as flores produzidas com a lâmina de $522 \mathrm{~mm}$ (75\% da ETc) seriam classificadas como classe I (A2), por apresentarem comprimento menor que $40 \mathrm{~cm}$, e as demais, como extra (A1).

MEDEIROS (2005) e SOUZA (2005), estudando a influência da aplicação de cinco lâminas de água residuária de origem urbana sobre o "status" nutricional do cafeeiro, também não observaram diferenças significativas na maioria das variáveis monitoradas. 
A
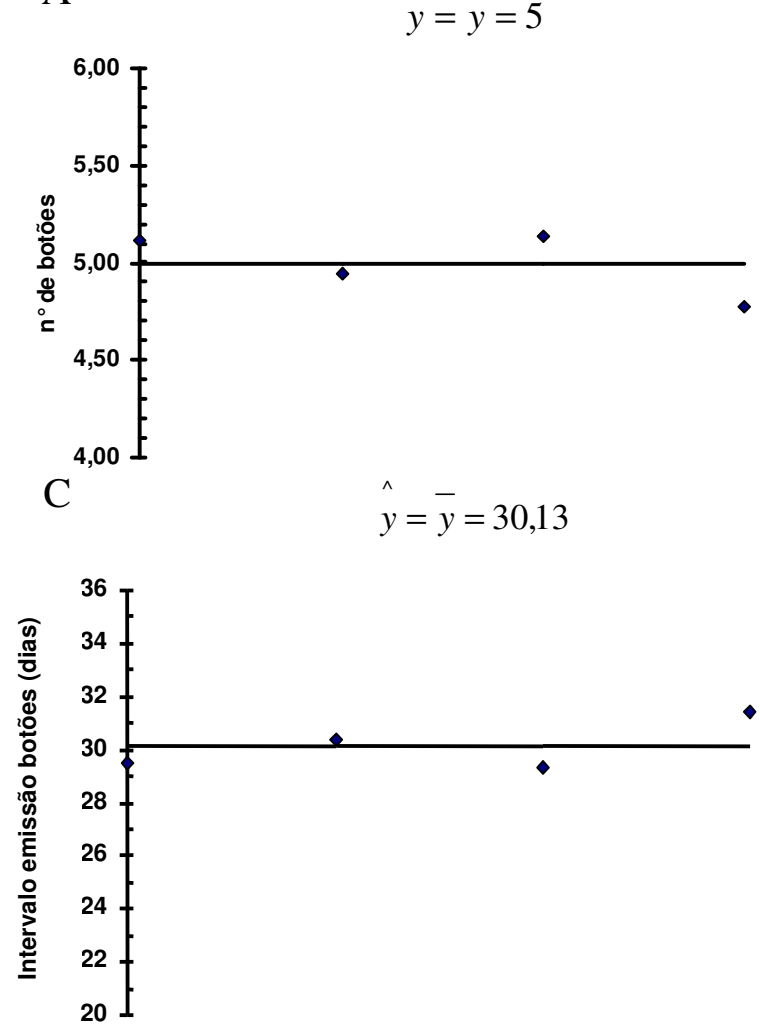

$\mathrm{E}$

$$
\hat{y}=\bar{y}=12,00
$$

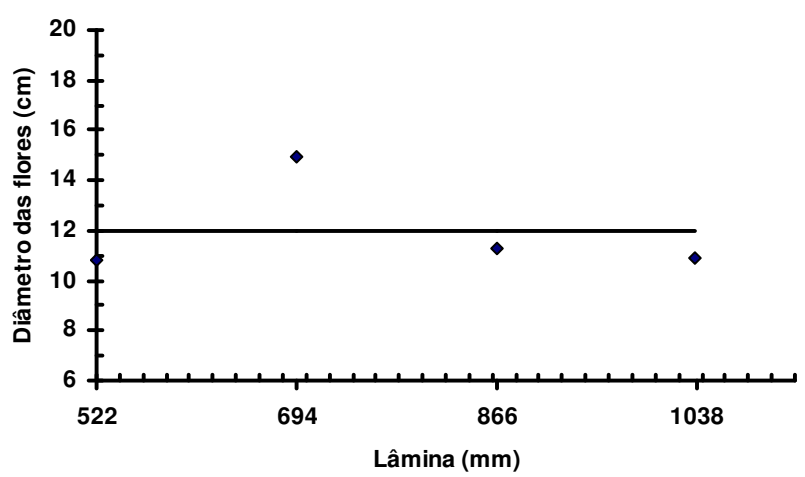

B

$$
\hat{y}=\bar{y}=4,40
$$
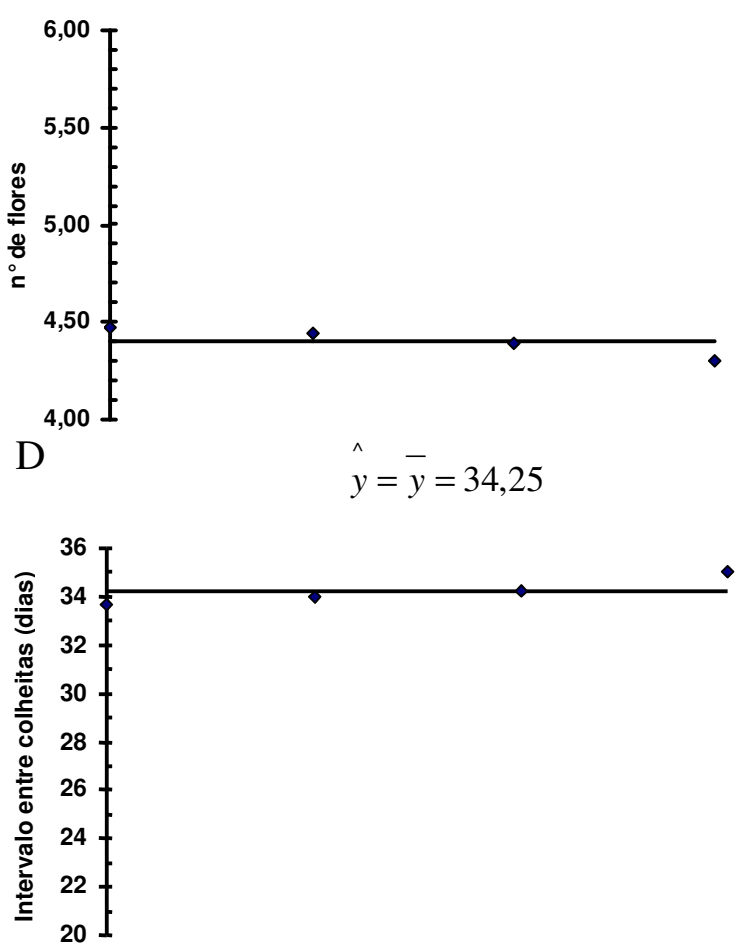

$\mathrm{F}$

$$
\begin{gathered}
\hat{y}=-0,321777+0,10563 x-0,0000629858 x^{2} * * \\
\mathrm{R}^{2}=0,99
\end{gathered}
$$

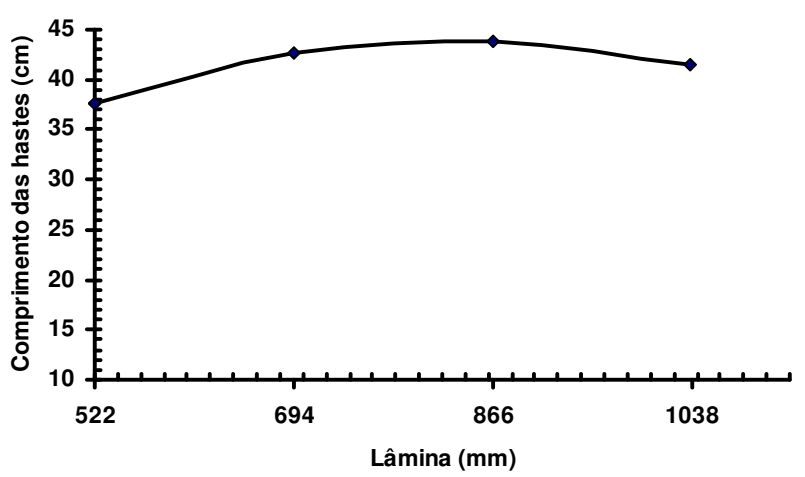

- Observado —Estimado

FIGURA 2. Médias e modelo de regressão ajustados às variáveis de produção: número de botões florais emitidos (A), número de flores colhidas (B), intervalo de emissão dos botões florais (C), intervalo entre colheitas de flores (D), diâmetro das flores (E) e comprimento das hastes $(\mathrm{F})$ em função da lâmina de água residuária aplicada. ** modelo significativo a $1 \%$ de probabilidade.

Demonstra-se, com o exposto, que as lâminas de água residuária que suplantaram as necessidades hídricas das plantas não apresentaram quaisquer benefícios adicionais; considere-se, ao contrário, que aplicações, em condições de campo, de lâminas excedendo a evapotranspiração das culturas podem também aumentar os riscos de contaminação da água freática, seja por agentes microbiológicos, seja pelo incremento nas concentrações de N, K e Na, tornando-as impróprias aos usos mais restritivos; outro aspecto importante é que lâminas maiores que a necessidade da cultura oneram os custos com o sistema de irrigação, em virtude do aumento no consumo de energia. 
Na Tabela 4, estão apresentadas as médias e diferenças médias para as variáveis de produção (número de botões florais emitidos, número de flores colhidas, intervalo de emissão dos botões florais, intervalo entre colheitas de flores, diâmetro das flores e comprimento das hastes) em resposta ao tipo de manejo adotado (MR - MC).

TABELA 4. Valores médios para as variáveis de produção em função da qualidade das águas (MR e MC) utilizadas no experimento.

\begin{tabular}{lrrrc}
\hline Variáveis & \multicolumn{1}{c}{ MC } & \multicolumn{1}{c}{ MR } & (MR - MC) & Significância Estatística \\
\hline Número de botões florais emitidos & 4,37 & 5,00 & 0,63 & $* *$ \\
Número de flores colhidas & 3,66 & 4,40 & 0,74 & $* *$ \\
Intervalo de emissão de botões florais & 34,47 & 30,13 & $-4,34$ & $* *$ \\
Intervalo entre colheitas de flores & 41,17 & 34,25 & $-6,92$ & $* *$ \\
Diâmetro das flores colhidas & 11,32 & 12,10 & 0,78 & $\mathrm{~ns}$ \\
Comprimento das hastes & 45,97 & 41,43 & $-4,54$ & $* *$ \\
\hline
\end{tabular}

**, *, ns: significativos a 1 e $5 \%$ de probabilidade e não-significativos, respectivamente.

MR - manejo com água residuária e MC - manejo convencional.

Nota-se, para as variáveis de produção número de botões florais emitidos e número de flores colhidas, que a adoção do MR foi significativamente superior (1\% de probabilidade) ao MC, apresentando incremento de 0,63 no número de botões florais emitidos e de 0,74 no número de flores colhidas. Verificou-se, também, que a adoção do MR reduziu em 4,34 dias o intervalo de emissão dos botões florais e em 6,92 dias o intervalo entre colheitas de flores, em relação ao MC, ambos significativos a $1 \%$ de probabilidade.

Quanto às variáveis referentes à qualidade das flores colhidas, não se detectaram diferenças significativas no diâmetro das flores, em relação ao tipo de manejo adotado, mas, para a variável comprimento das hastes, o MC foi estatisticamente superior ao MR (Tabela 1); todavia, o comprimento médio das hastes $(41,43 \mathrm{~cm})$, observado em MR, enquadra-se, segundo a IBRAFLOR (2000), na classificação extra (A1), em razão de apresentar comprimento médio maior que $40 \mathrm{~cm}$. Enfim, observa-se que, em relação à água de abastecimento, o uso de água residuária na irrigação de gérberas produz flores de melhor qualidade e, em maior quantidade, além de proporcionar economia em termos da aplicação de nutrientes.

\section{CONCLUSÕES}

A adoção do manejo com água residuária favoreceu as variáveis avaliadas, em relação ao manejo convencional, com exceção da variável comprimento de haste; portanto, o uso de água residuária constitui recurso importante no suprimento de nutrientes (principalmente $\mathrm{N}, \mathrm{P}$ e K ) e água para a cultura da gérbera, potencializando produtividade compatível ou até superior às técnicas de produção convencional, baseadas no uso de adubação mineral.

\section{AGRADECIMENTOS}

À Coordenação de Aperfeiçoamento de Pessoal de Nível Superior - CAPES, pela concessão do auxílio financeiro ao primeiro autor, com vistas à realização deste trabalho.

\section{REFERÊNCIAS}

AL-JALOUD, A.A.; HUSSAIN, G.; AL-SAATI, A.J.; KARIMULLA, S. Effect of wastewater irrigation on mineral composition of corn and sorghum plants in a pot experiment. Journal of Plant Nutrition, Athens, v.18, n.8, p.1.677-92, 1995.

AL-NAKSHABANDI, G.A.; SAQQAR, M.M.; SHATANAWI, M.R.; FAYYAD, M.; ALHORANI, H. Some environmental problems associated with the use of treated wastewater for irrigation in Jordan. Agricultural Water Management, Amsterdam, v.34, n.1, p.81- 94, 1997. 
APHA. AMERICAN PUBLIC HEALTH ASSOCIATION. Standard methods for the examination of water and wastewater. $20^{\text {th }}$.ed. New York: APHA, AWWA, WPCR, 1997. $1.194 \mathrm{p}$.

AYERS, R.S.; WESTCOT, D.W. A qualidade da água na agricultura. 2.ed. Campina Grande: UFPB, 1999. $153 \mathrm{p}$.

BASTOS, R.K.X (Coord.). Utilização de esgotos tratados em fertirrigação, hidroponia e piscicultura. Rio de Janeiro: ABES, RiMa, 2003. 267 p. Projeto PROSAB

BOUWER, H. Integrated water management: emerging issues and challenges. Agricultural Water Management, Amsterdam, v.45, n.3, p.217-28, 2000.

COELHO, M.A.; SONCIN, N.B. Geografia do Brasil. São Paulo: Moderna. 1982. 368 p.

EMBRAPA - EMPRESA BRASILEIRA DE PESQUISA AGROPECUÁRIA. Manual de métodos de análise do solo. Centro Nacional de Pesquisa de Solos. 2.ed. Rio de Janeiro: 1997. 247 p.

FEIGIN, A.; BIELORAI, H.; DAG, Y.; KIPNIS, T.; GISKIN, M. The nitrogen factor in the management of effluent-irrigated soils. Soil Science, Baltimore, v.125, n.4, p.248-54, 1978.

FEIGIN, A.; VAISMAN, I.; BIELORAI, H. Drip irrigation of cotton with treated municipal effluents: II. Nutrient availability in soil. Journal of Environmental Quality, Madison, v.13, n.2, p.234-8. 1984.

FUNARBE. SAEG - Sistema para análises estatísticas - versão 5.0. Viçosa: Fundação Arthur Bernardes, 1993. $80 \mathrm{p}$.

GUISELINI, C. Microclima e produção de gérbera em ambientes protegidos com diferentes tipos de cobertura. 2002. 53 f. Dissertação (Mestrado em Física do Ambiente Agrícola) - Escola Superior de Agricultura "Luiz de Queiroz", Universidade de São Paulo, Piracicaba, 2002.

IBRAFLOR - INSTITUTO BRASILEIRO DE FRUTICULTURA. Padrão IBRAFLOR de qualidade. Campinas. 2000. 87p. (Ficha Técnica).

JUNQUEIRA, A.H.; PEETZ, M.S. Plano estratégico para exportação de flores e plantas ornamentais do Brasil. Campinas: IBRAFLOR/APEX Brasil, 2004. 1 CD-ROM. Programa Flora Brasilis

KONIG, A.; SANTOS, A.V.; CEBALLOS, B.S.O.; CAVALCANTI, R.B.; GHEYI, H.R. The controlled reuse of wastewater in agriculture, a solution for large cities. In: INTER-REGIONAL CONFERENCE ON ENVIRONMENT-WATER: INNOVATIVE ISSUES IN IRRIGATION AND DRAINAGE, 1., 1998, Lisboa. Proceedings... Lisboa: CIGR, 1998. p.574-80.

LEON, S.G.; CAVALLINI, J.M. Tratamiento y uso de aguas residuales. Lima: CEPIS-OPS-OMS, 1996. $152 \mathrm{p}$.

MEDEIROS, S.S. Alterações físicas e químicas do solo e estado nutricional do cafeeiro em resposta à fertirrigação com água residuária de origem doméstica. 2005. $114 \mathrm{f}$. Tese (Doutorado em Recursos Hídricos e Ambientais) - Universidade Federal de Viçosa, Viçosa - MG, 2005.

PESCOD, M.B. Wastewater treatment and use in agriculture. Rome: FAO, 1992. 125 p. (Irrigation and Drainage Paper, 47).

SANDRI, S. Irrigação da cultura da alface com água residuária tratada com leitos cultivados com macrófita. 2003. 186 f. Tese (Doutorado em Engenharia de Água e Solo) - Universidade Estadual de Campinas, Campinas, 2003.

SOUZA, J.A.A. Uso de água residuária de origem doméstica na fertirrigação do cafeeiro: efeitos no solo e na planta. 2005. 114 f. Tese (Doutorado em Recursos Hídricos e Ambientais) Universidade Federal de Viçosa, Viçosa - MG, 2005.

TANJI, K.K. Irrigation with marginal quality waters: issues. Journal of Irrigation and Drainage Engineering, New York, v.123, n.3, p.165-9, 1997. 
VAN DER HOEK, W.; HASSAN, U.M.; ENSINK, J.H.J.; FEENSTRA, S.; RASCHID-SALLY, L.; MUNIR, S.; ASLAM, R.; ALIM, N.; HUSSAIN, R.; MATSUNO, Y. Urban wastewater: a valuable resource for agriculture. A case study from Horoonabad, Pakistan. Colombo, Sri Lanka: International Water Management Institute, 2002. 29 p. (Research Report, 63) 